\title{
Trypanosoma cruzi: adaptation to its vectors and its hosts
}

\author{
François NoIreau ${ }^{1,2 *}$, Patricio DiosQue ${ }^{3}$, Ana Maria JANSEN ${ }^{4}$ \\ ${ }^{1}$ UR 016, Institut de Recherche pour le Développement (IRD), Montpellier, France \\ ${ }^{2}$ Facultad de Medicina, Universidad Mayor San Simón, Cochabamba, Bolivia \\ ${ }^{3}$ Unidad de Epidemiología Molecular, Instituto de Patología Experimental, Facultad de Ciencias de la Salud, \\ Universidad Nacional de Salta, Salta, Argentina, and Consejo Nacional de Investigaciones Científicas y Técnicas \\ (CONICET), Argentina \\ ${ }^{4}$ Laboratório de Biologia de Tripanosomatídeos, Instituto Oswaldo Cruz, Av. Brasil 4365, PO Box 926, \\ Rio de Janeiro, 21040-360, RJ, Brasil
}

(Received 16 July 2008; accepted 26 February 2009)

\begin{abstract}
American trypanosomiasis is a parasitic zoonosis that occurs throughout Latin America. The etiological agent, Trypanosoma cruzi, is able to infect almost all tissues of its mammalian hosts and spreads in the environment in multifarious transmission cycles that may or not be connected. This biological plasticity, which is probably the result of the considerable heterogeneity of the taxon, exemplifies a successful adaptation of a parasite resulting in distinct outcomes of infection and a complex epidemiological pattern. In the 1990s, most endemic countries strengthened national control programs to interrupt the transmission of this parasite to humans. However, many obstacles remain to the effective control of the disease. Current knowledge of the different components involved in elaborate system that is American trypanosomiasis (the protozoan parasite $T$. cruzi, vectors Triatominae and the many reservoirs of infection), as well as the interactions existing within the system, is still incomplete. The Triatominae probably evolve from predatory reduvids in response to the availability of vertebrate food source. However, the basic mechanisms of adaptation of some of them to artificial ecotopes remain poorly understood. Nevertheless, these adaptations seem to be associated with a behavioral plasticity, a reduction in the genetic repertoire and increasing developmental instability.
\end{abstract}

Trypanosoma cruzi / Triatominae / mammalian host / vectorial transmission / adaptative strategies

\section{Table of contents}

1. Introduction

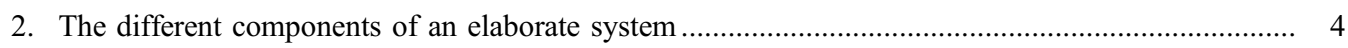

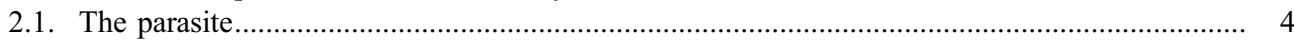

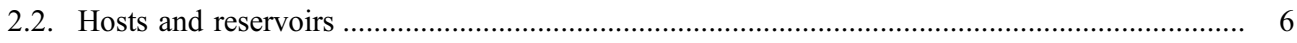

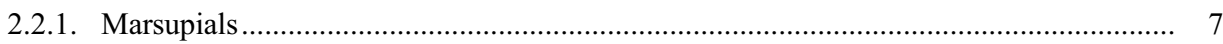

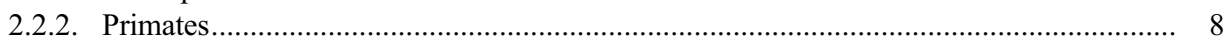

2.2.3. Bats ................................................................................................. 9

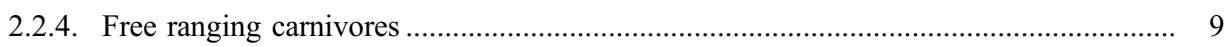

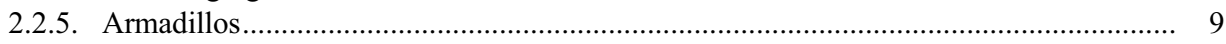

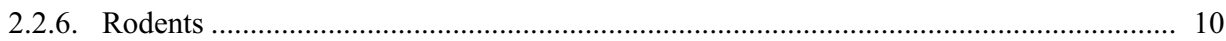

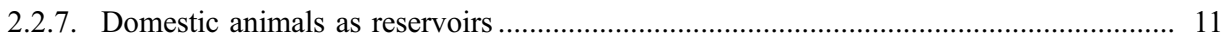

\footnotetext{
* Corresponding author: francois.noireau@ird.fr
} 
2.2.8. Birds and others non-reservoir feeding hosts

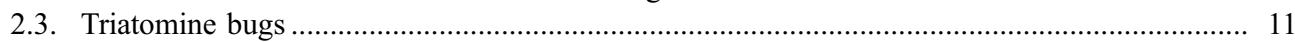

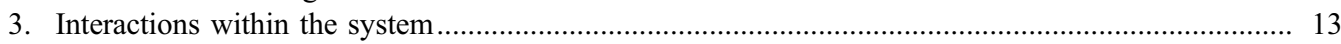

3.1. Interactions between $T$. cruzi and triatomine bugs, and vectorial capacity........................... 13

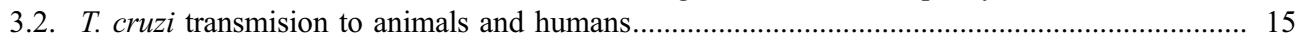

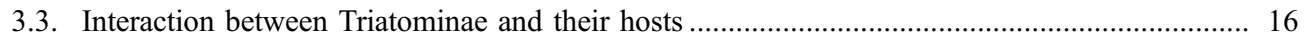

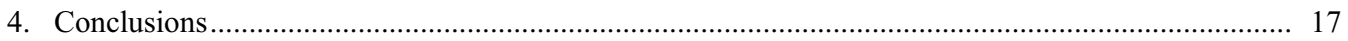

\section{INTRODUCTION}

American trypanosomiasis is a zoonosis caused by the flagellate protozoa Trypanosoma cruzi, which is restricted to New World. The parasite is transmitted through the fecal droppings of infected blood-sucking insect vectors belonging to the subfamily Triatominae (Hemiptera and Reduviidae). Endemic foci of the human disease (also called Chagas disease) range from Mexico to the Northern half of Argentina and Chile, mostly in poor rural areas where houses are infested with domestic species of Triatominae (Figs. 1 and 2) [106]. As for animal trypanosomiasis, its distribution is widespread from the Southern United States to Patagonia (roughly $40^{\circ} \mathrm{N}$ to $45^{\circ} \mathrm{S}$ ). More than 180 domestic, synanthropic and wild species of mammals, especially nest-building rodents and opossums (Marsupialia, Didelphidae), are likely to be infected by $T$. cruzi and to be involved in the transmission cycle of the disease [119].

After exclusively infecting animals for millions of years, $T$. cruzi began to infect humans relatively recently and, consequently, Chagas disease became an emerging infectious disease (EID). As with many EID, the key event in its emergence was a change in the vector-hostparasite ecology resulting from anthropogenic changes to wildlife habitats that allowed for vector-human contact and subsequent transmission of the zoonotic parasite to humans [118].

During the 20th century, Chagas disease was reported in all countries in Latin America, where it was the most important parasitic disease in terms of impact on national economies and public health systems [119]. The disease follows a chronic course, mainly affecting the heart (myocarditis) and digestive system (megaesophagus and megacolon). From the beginning of the 1990s, regional control programs directed against domestic vectors were initiated in most Latin American countries. They led to a reduction of disease prevalence from 1990 estimates of 16-18 million people infected to current estimates of $\sim 9$ million [107]. However, many obstacles remain to the effective control of the human disease. Although Chagas disease is physically disabling and its lethality is unquestionable (at least one million Latin American people carrying the parasite will die unless a new scientific and/or political breakthrough occurs), the disease is no longer perceived as a major public health burden in many countries [76]. Part of the reason for this may be that Chagas disease most often afflicts vulnerable indigenous communities living below the poverty line. This situation has led to the recent classification of Chagas disease as a neglected disease by the Pan American Health Organization [6].

The epidemiology of Chagas disease is currently changing. The vector transmission of the parasite was until now mostly depended upon domestic vectors (especially Triatoma infestans, Triatoma dimidiata and Rhodnius prolixus) and displayed a hyperendemic pattern of the disease in many regions of Latin America. Gradually, and chiefly owing to the control programs employed against these domestic vectors, this pattern is being supplanted by emergent infection patterns and by previously secondary transmission patterns [107]. As such, T. cruzi congenital infection and transmission by blood transfusion is becoming important, not only in Latin America but also in European and Northern American countries where Latino immigration occurs [119]. Also of concern are the emergent vector transmission patterns that involve wild Triatominae displaying 


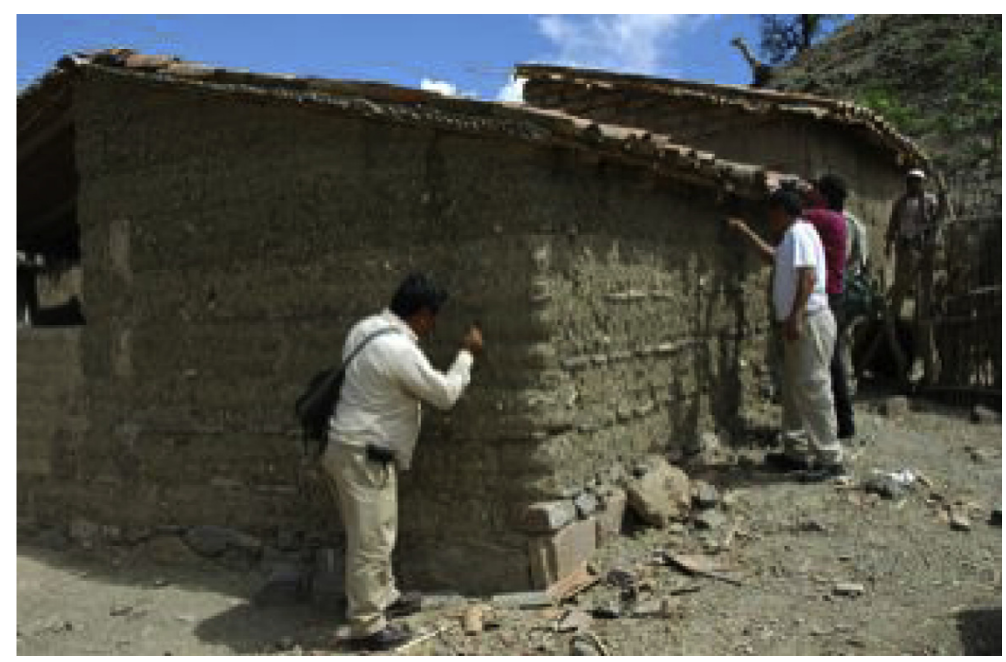

Figure 1. Bug collectors searching for Triatominae in an adobe-walled house. (A color version of this figure is available at www.vetres.org.)

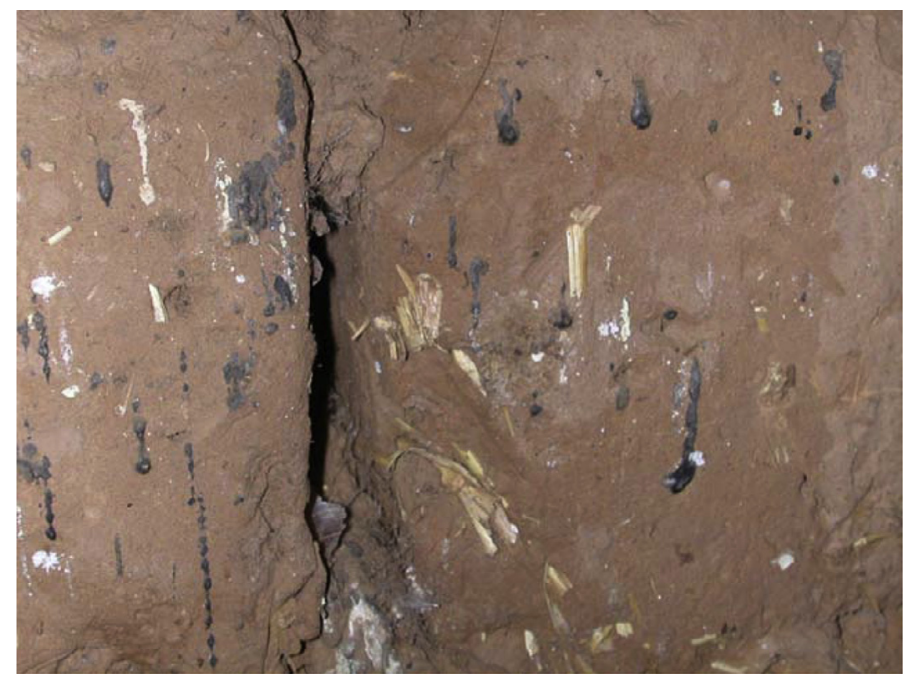

Figure 2. Crack offering refuge to triatomine bugs and fecal streaks in a mud wall. (A color version of this figure is available at www.vetres.org.)

synanthropic trends and coming into contact with humans. Finally, human cases arising from ingestion of contaminated food recently recorded in Brazil are puzzling to health authorities [122]. Although human-related ecological alterations seem to favor change in the patterns of transmission, the basic mechanisms involved remain poorly understood.

This article reviews the different components that make up the elaborate system that is American trypanosomiasis and the interactions between components within the system. 


\section{THE DIFFERENT COMPONENTS OF AN ELABORATE SYSTEM}

\subsection{The parasite}

Since the discovery of $T$. cruzi as the etiological agent of American trypanosomiasis (Chagas disease) by Carlos Chagas in 1909, our knowledge about the wide genetic variability and phylogenetic relationships among the different lineages of the parasite has grown exponentially [24]. This growth of knowledge has been supported by theoretical approaches based on population genetics analysis and the increasing development of molecular biology tools used to identify different genetic subtypes of the parasite $[14,15,38,39,108,110,111]$. Today, T. cruzi, a flagellate eukaryote of the order Kinetoplastida, is classified as a single species, with an intraspecific classification that recognizes different lineages and sublineages.

A general objective of most taxonomic classifications is to reflect, as accurately as possible, the evolutionary history of the taxonomic units considered. This is not a simple task for any organism and it becomes even harder if the studied organism has an atypical eucaryotic genetic biology, as is apparently the case for T. cruzi [46]. Moreover, when the organism under study is of medical importance, it is desirable that both the taxonomic classification and the data that lead to the identification of the taxonomic units be of epidemiological and/or clinical relevance. In this sense, and in spite of controversies about phylogenetic relationships among the different lineages within $T$. cruzi, molecular data allow us to draw six general conclusions based on current evidence: (i) there are major phylogenetic lineages of the parasite with great genetic distances between them [112]; (ii) there is a general agreement about intraspecific nomenclature: there are two major lineages, T. cruzi I (TCI) and T. cruzi II (TCII), with five sublineages within T. cruzi II (IIa, IIb, IIc, IId and IIe) [3, 14]; (iii) the evolution of the different lineages has been basically clonal, with some ancient genetic exchange and recombination events that had an important impact on the generation of genetic diversity within this taxon $[13,14,117]$; (iv) there are lineages with a hybrid origin arising from ancient hybridization events between parasites belonging to distantly related lineages [75, 117]; (v) at least some lineages have some capacity for genetic exchange and homologous recombination, as demonstrated experimentally [46]; (vi) there is evidence suggesting genetic exchange in natural cycles involving TCI strains, although there are no data about the frequency of these events or their impact on the genetic structure of natural populations of the parasite $[22,33]$. These six statements constitute a useful framework that makes sense in both evolutionary and epidemiological terms. Moreover, the nomenclature used ( $T$. cruzi I, IIa, IIb, IIc, IId, and IIe) is a very good approximation of the likely "real" phylogenetic structure of the parasite. Indeed, the genetic markers available for lineage typing are very useful considering the complex and still unresolved epidemiology of the different lineages, as well as the possible relationship between the range of clinical manifestations and the infecting lineages [7, 14, 15].

The general pattern of the geographic distribution of $T$. cruzi lineages and sublineages is shown in Figure 3. Among all lineages and sublineages, TCI has the largest distribution, from the southern part of the USA to northern Argentina and Chile. TCIIa has been reported in the northern Amazon basin and in the USA, with some reports from south of the Amazon basin. TCIIc is present from the Amazon basin to southern endemic regions while TCIId and TCIIe have only been reported in the Southern Cone countries. TCIIb occurs mainly in the Southern Cone countries; however it has also been reported in Colombia [123].

It is worth mentioning that different numbers of phylogenetic lineages within $T$. cruzi have been proposed: 3 or 4 major lineages, based on mitochondrial or nuclear DNA sequences, respectively [75]; 3 lineages, using microsatellite analysis [87]; and also 3 lineages based on sequence analysis of an $1100 \mathrm{bp}$ DNA fragment [96]. Today, it seems clear that most of these inconsistencies among different phylogenetic analyses are related to the hybrid origin of some lineages, which generates different phylogenetic relationships according to the 


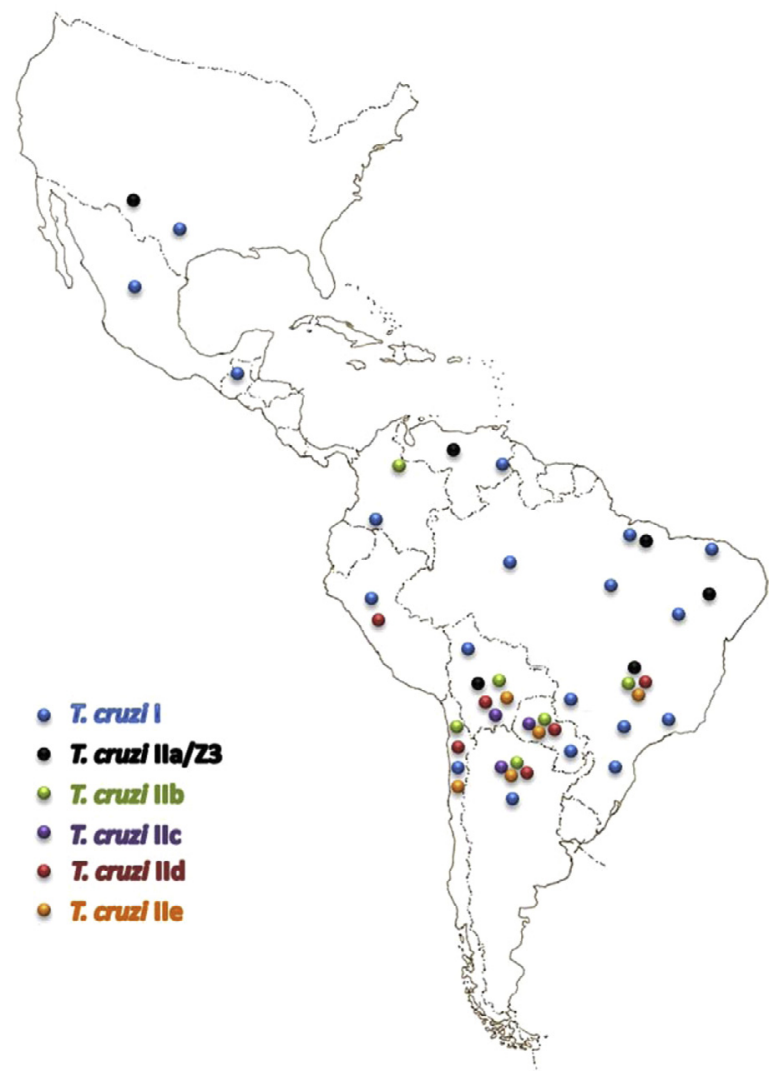

Figure 3. General pattern of distribution of $T$. cruzi lineages and sublineages; the isolates typed as $T$. cruzi II using the mini-exon gene (uncharacterized sublineages) are not represented on the map.

number and type of examined markers, as well as the number and genetic diversity of the studied isolates.

Based on molecular data, a very plausible model for the evolution of the different $T$. cruzi lineages suggests an ancestral fusion of strains belonging to lineages TCI and TCIIb, producing a heterozygous hybrid which through homogenization of its genome became the homozygous progenitor of the TCIIa and TCIIc lineages [117]. A second hybridization event between TCIIb and TCIIc strains could have generated the TCIId and TCIIe lineages. Under this hypothetical model, every hybridization event was separated by long periods of clonal evolution. In light of such a complex evolutionary framework and the existing evidence, the current consensus of six lineages or DTUs (discrete typing units), namely T. cruzi I, IIa, IIb, IIc, IId, and IIe, seems to be the most parsimonious and useful in epidemiological terms, and is probably also the most accurate phylogenetically [113].

Accepting the intraspecific nomenclature proposed before, and assuming a general genetic stability in space and time of the lineages as suggested by the strong linkage disequilibrium systematically observed in T. cruzi, different authors have hypothesized about the evolutionary history of the different lineages. These evolutionary models are based on present data regarding associations among parasite lineages, insect vectors and mammalian hosts; present and inferred ancient geographical distribution of vectors and 
mammalian hosts; and reconstructions of the molecular evolutionary history of parasite lineages $[12,45,75]$. All these analyses, beyond generating basic knowledge about the evolutionary history of $T$. cruzi, have the goal of allowing us to obtain a picture of the eco-epidemiological characteristics involved in the transmission dynamic of the different $T$. cruzi lineages. Certainly, the understanding of the parasite evolutionary history and the time of divergence of the different lineages could explain some present associations among different hosts and vectors. The occurrence of common evolutionary histories among parasite lineages, hosts and vectors, could help investigators identify phenomena that led to the enhanced fitness of some lineages under certain epidemiological situations, and provide examples of co-evolutionary processes. An examination of such processes could also lead to the identification of adaptative mechanisms that would allow different lineages to infect different mammalian species (including humans), and may also explain the diversity of clinical manifestations of Chagas disease.

Widely different times for the divergence between the TCI and TCII lineages have been proposed $[12,59,75]$. Whatever is the divergence time between TCI and TCII, certain data support the association of TCI with the triatomine tribe Rhodniini and the marsupial genus Didelphis (opossum), while TCII has been proposed to have evolved in association with the triatomine tribe Triatomini and edentate placental mammals such as armadillos (Xenarthra, Dasypodidae) [45, 121]. This hypothesis suggests that both, T. cruzi I and T. cruzi II, would have evolved contemporarily in South America up to 65 million years [45]. A relatively recent report presented the finding of T. cruzi IIc, IIb and IId lineages in armadillos in the wild in Paraguay [121]. This study included a very comprehensive analysis of historically published host records of $T$. cruzi lineages that clearly suggests the proposed association of the genus Didelphis with TCI, and armadillos with TCII [121]. Whether these data reflect an ancient association that could imply adaptation to marsupials (T. cruzi I) and placentals (T. cruzi II), remains to be confirmed.
A recent and comprehensive phylogenetic study of the genus Trypanosoma and coevolution with its hosts suggests that "ecological host fitting", a process by which organisms are able to colonize new hosts as a result of traits they already possess, may have played a principal role in trypanosome evolution, even more than co-evolution $[50,58]$. If this general pattern of evolution proposed for the genus Trypanosoma is also the rule for the evolution of the different lineages within the $T$. cruzi taxon, adaptations of different lineages to specific hosts could have not occurred.

\subsection{Hosts and reservoirs}

The concept of what constitutes a reservoir host has changed over time. Carlos Chagas, who described the etiological agent of the human disease that later received his name, also described one of its wild hosts, an armadillo species that he identified as Tatusia novencincta. In his description, Carlos Chagas named this infected armadillo as the "depository" of T. cruzi. The use of this term reflects the once generally accepted idea that a wild mammal species harboring a parasite capable of infecting humans is an almost inert repository of this parasite that acts as the source of human infection. The notion of a host as a complex living system, able to suffer and apply selective pressure on parasites according to their environmental conditions, thereby playing active and distinct roles in the transmission cycle is much more recent. The complexity of variables that influence a given parasite transmission cycle, in time and space scales, is especially important when considering the study of multi-host parasites such as $T$. cruzi. This protozoan fully embodies the characteristics of a successful parasite since it is maintained in nature by numerous vector species and mammal host species distributed across almost all biomes and habitats in the Americas. T. cruzi is also able to colonize almost all tissues in its many mammalian hosts, even unconventional sites, such as the scent glands of Didelphid marsupials [29].

Despite the identification of a large list of wild mammal species naturally infected by T. cruzi, there are many unanswered questions 


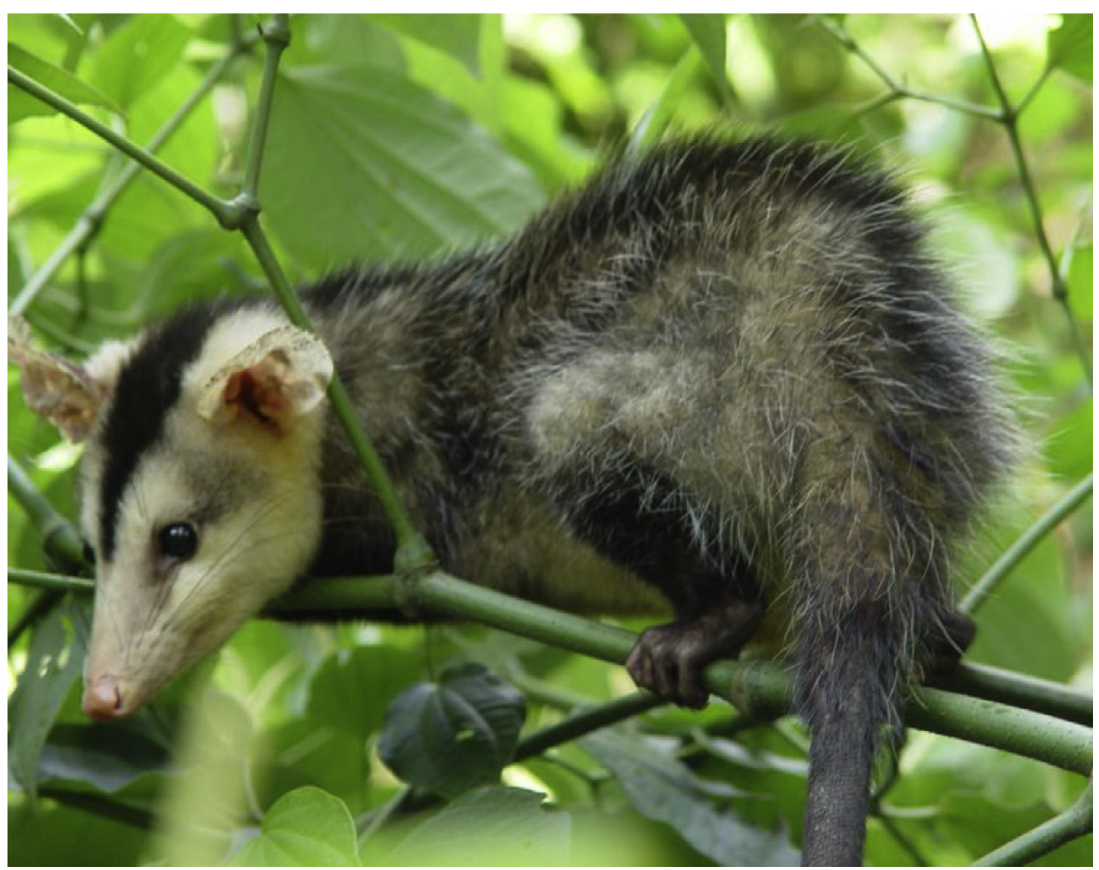

Figure 4. Didelphis albiventris, which may simultaneously act as a reservoir and a vector for T. cruzi. (A color version of this figure is available at www.vetres.org.)

concerning the role played by these species in the maintenance and/or transmission of $T$. cruzi in the wild $[8,119]$. Most studies are geographically restricted and do not include data on the broader environmental conditions, such as local fauna diversity, the relative abundance of infected animals or the population structure. Here, we reappraised the concept of reservoir by including, when possible, the peculiarities of the interaction of $T$. cruzi with its known wild and domestic hosts. We define a reservoir as one species or an assemblage of species responsible for the long-term maintenance of a given parasite in a given environment [4].

\subsubsection{Marsupials}

These ancient mammals are considered, together with Xenarthra (armadillos and anteaters), to be the earliest hosts of $T$. cruzi as South American mammals were restricted to these taxa after separation of this continent. Marsupial species of the genus Didelphis (Fig. 4) display a unique interaction with $T$. cruzi: they are able to concomitantly maintain amastigotes multiplying in the tissues and epimastigotes multiplying and differentiating in their scent glands (Fig. 5) [29]. These findings showed that Didelphis sp. may act simultaneously as reservoir and a vector of T. cruzi, and suggest a possible ancient transmission mechanism of this parasite before the acquisition of hematophagous habits by triatomines. Metacyclogenesis of $T$. cruzi in the lumen of the scent gland occurs without adhesion of the parasite and may be significant (involving up to $50 \%$ of the $T$. cruzi present), however the "vectorial" capacity of Didelphidae in natural conditions is still unknown (Fig. 4) [23]. The infectivity of opossum scent gland metacyclic forms was proven by successful experimental infection of Swiss mice. Monogenetic trypanosomatids (Leptomonas, Crithidia and Herpetomonas) may also efficiently colonize the scent glands of Didelphis aurita under experimental conditions when the trypanosomatids are directly 


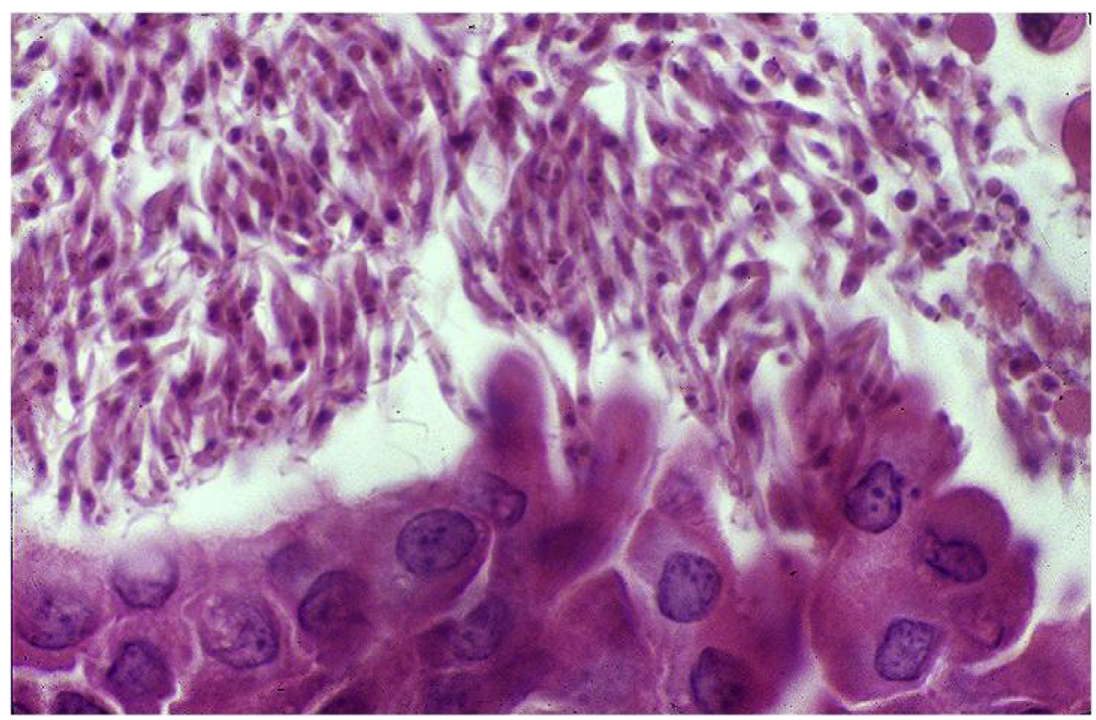

Figure 5. T. cruzi epimastigotes multiplying and differentiating in the scent gland of Didelphis sp. (A color version of this figure is available at www.vetres.org.)

inoculated into the glands [57]. Marsupials of the genus Didelphis are non-specialized mammals and may be found on the ground and in the canopy. They are excellent climbers but move clumsily on the ground. Didelphis may provide excellent reservoirs of $T$. cruzi since these animals may maintain long-lasting infections and high parasitemias. Notably, their competence as reservoir varies in space and time. This is exemplified by the differences of $T$. cruzi infection prevalence that ranged between $11-90 \%$ in D. aurita collected from various sites in Rio de Janeiro State, Brazil [40]. Furthermore, due to its synanthropic behavior, the genus Didelphis should always be considered an excellent reservoir of T. cruzi in peridomestic, domestic and disturbed habitats. In a pristine wild environment, other taxa assume the role of reservoir. Opossums are known for their adaptability to human environments and are considered to be indicators of environmental disturbance [86]. In experimental conditions, $D$. aurita has been described as being able to maintain stable infection by TCI isolates while having the capacity to control and even eliminate TCII isolates. This observation was reinforced by the regular isolation of TCI and not TCII isolates in naturally infected animals [40]. However, these experimental studies were undertaken with only two TCII isolates, which is not representative of the diversity of the heterogeneous TCII lineage. In fact, naturally TCII-infected $D$. aurita and Didelphis albiventris animals have been detected in several biomes showing that this marsupial may act as an effective biological filter for some subpopulations of $T$. cruzi but not necessarily for the entire TCII lineage. Animals from Didelphidae family display unique interaction patterns with T. cruzi. For instance, Philander frenatus, in contrast to $D$. aurita, maintains a stable infection with a high and long lasting parasitemia in experimental infections with T. cruzi Y strain [67]. It is likely that these two marsupials apply distinct selective pressures on $T$. cruzi subpopulations and consequently play dissimilar roles in the maintenance and transmission of this parasite in nature.

\subsubsection{Primates}

Primates were incorporated much later into the transmission cycle of $T$. cruzi than 
marsupials, as they are supposed to have colonized the American continent 35 million years ago [42]. However, they also display an ancient co-evolutive history with $T$. cruzi. In the golden lion tamarin (Leontopithecus rosalia), an endangered callithrichid species maintained in a conservation program in a biological reserve in the state of Rio de Janeiro, Brazil, it was shown that a same animal host species may display different competences as a reservoir, even in the same forest unit. In this reserve, $T$. cruzi infection with the genotype TCII lineage was demonstrated in $46 \%$ of the golden lion tamarins [70]. However, infectivity, demonstrated by high parasitemia levels (positive hemocultures), varied between colonies. The subsequent observation of a positive association between the frequency of tamarins with T. cruzi-positive blood cultures and the presence of Trichostrongylidae showed that concomitant parasitic infections may increase the transmissibility of $T$. cruzi and, consequently, the competence of this host species as a reservoir [81]. Infection by genotype TCI was detected only in a small number of the tamarin specimens. In contrast, in the Amazon basin region of Brazil, only the TCI lineage was detected in the primate species examined [71].

\subsubsection{Bats}

In a recent survey of 93 specimens belonging to four different bat families (Molossidae, Noctilionidae, Phyllostomidae and Vespertilionidae), $15 \%$ had T. cruzi positive hemocultures [72]. The majority ( $80 \%)$ of these positive hemocultures were derived from the generalistic species Phyllostomus hastatus, suggesting that this bat species may play an important role in the maintenance and dispersal of $T$. cruzi. An electrophoretic analysis of multiple enzyme loci (MLEE) of the isolates did not show any correlation between zymodeme, bat genera, species and geographic origin. The analysis of miniexon genes showed that 10 out of $14 T$. cruzi bat isolates corresponded to the TCII lineage. The exixtence of mixed infections with TCI, TCII (unspecified sublineage) and Z3 (TCIIa) in bats indicates that these mammals may be involved in the dispersal of various T. cruzi genotypes [72].

\subsubsection{Free ranging carnivores}

The oral transmission of $T$. cruzi is probably especially important among carnivores. A study conducted in the Brazilian Pantanal region focused on $T$. cruzi infection in free ranging coatis (Nasua nasua), a carnivore species commonly observed in this biome, reported a high antibody prevalence. The high number of positive hemocultures obtained showed that coatis may be highly infective. Single infections by TCII (unspecified sublineage) (32.1\%) and TCI $(28 \%)$ as well as Z3 (TCIIa) $(7.1 \%)$ were most commonly observed, however, mixed infections TCI/TCII (10.7\%) and TCI/Z3 (TCIIa) $(3.6 \%)$ were also detected. The follow up of recaptured coatis showed that infection with high parasitemia levels is commonly long lasting in this species. Due to their high biomass, coatis certainly play a role in the amplification and dispersal of the main $T$. cruzi subpopulations, demonstrating that predatorprey links may be excellent mechanisms for T. cruzi transmission and perpetuation in the wild [54]. Similarly, other carnivores, such as raccoons (Procyon lotor) and gray foxes (Urocyon cinereoargenteus) are frequently exposed to $T$. cruzi infections $[51,99]$.

\subsubsection{Armadillos}

In spite of being the very first wild mammals in which $T$. cruzi infection was observed, the interaction of these Xenarthrans (Fig. 6) with $T$. cruzi remains largely uncharacterized. T. cruzi-infected armadillos have been reported from the USA to Uruguay, and as with other wild mammal species, infection rates do vary from region to region. In Louisiana, USA, infection by T. cruzi was detected in $26 \%$ of 80 armadillos [120]. In the same state, but in another region, only $3.9 \%$ of 415 wild nine-banded armadillos (Dasypus novemcinctus) were infected [88]. A retrospective study conducted in French Guiana described this species as the main $T$. cruzi reservoir behind the marsupial Didelphis marsupialis [93]. More recently, high infection with TCII was detected in nine-banded armadillos and six-banded armadillos (Euphractus sexcinctus) in Paraguay [121]. 


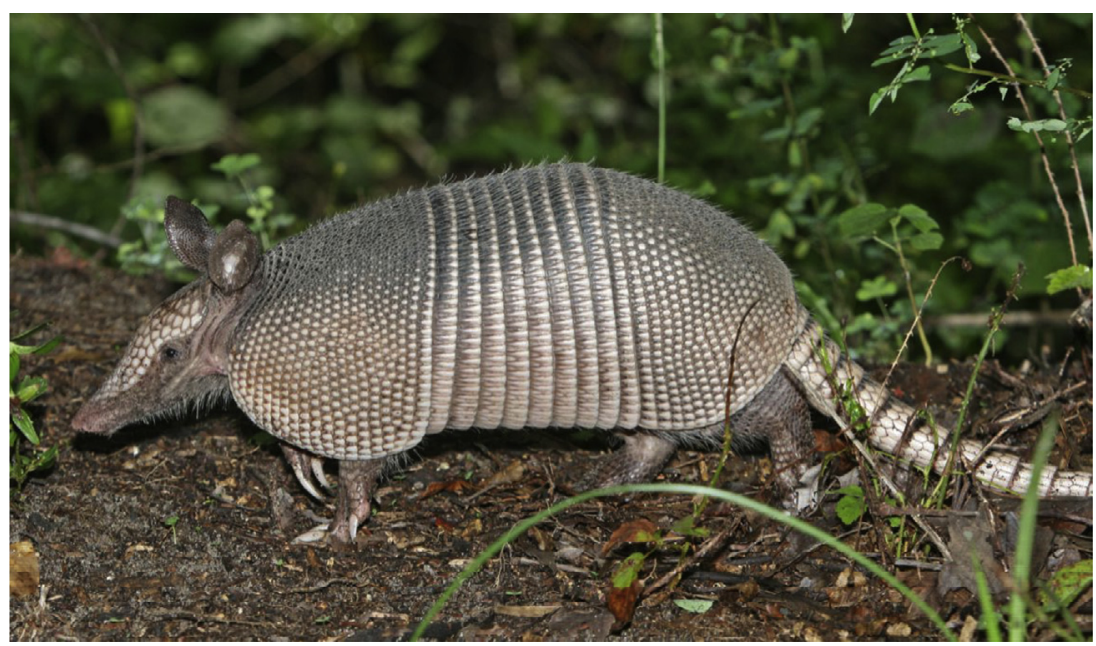

Figure 6. Dasypus novemcinctus (nine-banded armadillo). (A color version of this figure is available at www.vetres.org.)

\subsubsection{Rodents}

Rodents are ubiquitous mammals that are found, in most areas, in high relative abundance and have a broad range of habitats. Furthermore, both wild and synanthropic species have been reported as beeing highly involved in T. cruzi transmission in several regions. Caviomorph rodents (i.e. guinea pigs and allies) are especially interesting as they have an ancient co-evolutionary history with $T$. cruzi since, like primates, they arrived in the Americas about 35 million years [42]. Naturally infected Thrichomys laurentius and T. pachiurus, two sibling caviomorph rodent species, have been reported in two very dissimilar biomes in Brazil: in the Caatinga, the semi arid region of the northeastern Brazil (white shrub) and in the Pantanal, a flood plain region in the central part of the country, respectively [55]. TCI, TCII and Z3 (TCIIa), as well as one mixed TCI/Z3 (TCIIa) infection, were detected in these rodents [53]. The abundant rodent species Oecomys mamorae (arboreal rice rat) was also demonstrated to be involved in the maintenance and transmission of $T$. cruzi [53]. These results do not support an association between the $T$. cruzi main genotypes and the mammalian host taxa. In addition, the coexis- tence of multiple strains circulating in a same biome and even in a same animal is probably a very common feature in wild mammals [101]. The distinct subpopulations and clones of $T$. cruzi are continuously submitted to distinct selective pressures in their vertebrate and invertebrate hosts. These selective pressures are the outcome of traits inherent to host species but are also, and perhaps much more strongly, related to populational and even individual conditions. Nutritional status, age, stress conditions, previous and current parasitic infections of the hosts besides inter- and intraspecific competition and/or cooperation among parasites should also be considered as components of the habitat that a parasite encounters. The coexistence of $T$. cruzi lineages and sublineages has been observed in wild and peridomestic mammals in Chile [101]. In the same study, no association was found between the genotype of the parasite and host species, suggesting that the profile of animal infection by $T$. cruzi depends on the predominant genotype in a given locality that is defined by the interplay of all biotic factors present at the time of transmission. As such, contradictory data from different studies may reflect different epidemiological scenarios and methods, limited or restricted data and/or biased or incomplete sampling of habitats. 


\subsubsection{Domestic animals as reservoirs}

As observed for wild mammals, domestic species may also play various roles in the T. cruzi transmission. They may act as a link between wild and peridomestic or domestic habitats or they may merely be dead end hosts.

\subsubsection{Dogs and cats}

Dogs and cats are very often found with a high T. cruzi infection prevalence. As for all other mammal species, their role in the transmission cycle of $T$. cruzi varies as shown by the patterns of infection in distinct study areas. In the Argentian Chaco, both cats and dogs have been reported to be epidemiologically important and highly infective for triatomines [49]. Similar findings were described in western Venezuela where both TCI and TCII genotypes infect dogs [26]. An active canine T. cruzi transmission cycle with severe symptoms affecting a broad range of dog breeds and age groups was observed in several counties in Texas, USA [61]. In contrast, the absence of positive dogs by IFAT testing led to conclude that dogs are not important in the dispersion of $T$. cruzi in several urban areas of Brazil and Colombia [99]. In our experience, in spite of the high antibody prevalence, we have not observed parasitemias upon direct examination of fresh blood smears, nor have we observed positive hemoculture in various areas of Brazil including the Amazon basin and the Northeast and Southwest regions. A direct correlation of seropositivity between humans and dogs was observed in Mexico, emphasizing the importance of sentinel dogs as a surveillance measure in that country [37].

\subsubsection{Pigs}

An interesting situation is represented by feral pigs in Pantanal, the seasonally flooded basin in the central part of Brazil. These animals, derived from domestic swine (Sus scrofa) that went back to the wild, have been implicated in the maintenance of $T$. cruzi in nature [52]. In addition, pigs may be attractive hosts for triatomines such as Panstrongylus geniculatus, as observed in new human settlements in the Amazon basin [116].

\subsubsection{Goats}

The limited number of studies on T. cruzi in goats suggests that the role played by these peridomestic mammals in the transmission cycle of $T$. cruzi is mainly secondary in spite of their high exposure to infection. There are no reports of high parasitemias in naturallyinfected animals, and the presence of the parasite was detected only by PCR testing or indirectly by the presence of specific antibodies $[55,101]$.

\subsubsection{Birds and others non-reservoir feeding hosts}

Birds are refractory to $T$. cruzi infection owing to a complement-mediated lytic effect of their blood on the parasite [60]. Nevertheless, they may play an indirect but significant role in the maintenance of $T$. cruzi parasites in both wild and peridomestic environments since they are important feeding sources for Triatominae. In fact, the schedule of blood intake by infected triatomine bugs influences the T. cruzi population density and the proportion of the population in various developmental stages. Short feeding intervals increase the total population density of $T$. cruzi in the vector in contrast to starvation, which reduces the total number of flagellates and the number and percentage of trypomastigotes [63]. In the domestic environment, chicken coops are very attractive to triatomines. Additionally, in rural areas, poultry shelters are frequently constructed very close to human dwellings. This practice certainly results in an increase in the local triatomine population size and may either act as barrier against domiciliary invasion by the insects or may increase the chances of contact between triatomines, domestic mammals and humans.

\subsection{Triatomine bugs}

The Triatominae (Hemiptera, Reduviidae), still named kissing bugs, are blood-sucking insect vectors of $T$. cruzi. Their life cycle 
consists of five nymph stages before they reach sexual maturity. This process requires about six months, depending upon the species. Their size ranges from a few millimeters after hatching to more than $3 \mathrm{~cm}$ for adults, in some species. Currently, 139 triatomine species are listed, belonging to 6 tribes and 18 genera $[18,43$, 68]. Most of these species are widespread in the Americas, except for the Indian genus Linshcosteus, and the tropicopolitan Triatoma rubrofasciata and its related Asian species. The species richness of the New World Triatominae increases from the poles towards the equator, peaking over the $5^{\circ}-10^{\circ} \mathrm{S}$ latitudinal band [97]. Several pieces of evidence strongly support a polyphyletic origin for the Triatominae though the classic assumption of monophyly persists $[56,104]$. The Triatominae subfamily is assumed to have evolved from Reduviidae predator groups dispersed in several areas of the world rather than stemming from a cladistic class of individuals sharing a common ancestry [21]. In human and veterinary medicine, the importance of three genera, namely Triatoma, Rhodnius, and Panstrongylus, lies in the fact that some of their members feed on humans and synanthropic mammals and may thus transmit T. cruzi [119]. However, wild populations of all triatomine species (except those that are strictly ornithophagous) also maintain an enzootic cycle involving wild mammals in a variety of terrestrial or arboreal biotopes. Habitat trends also exist in the different triatomine genera. As such, Rhodnius species are primarily associated with palm trees, Panstrongylus species are predominantly found within burrows and tree cavities, and the genus Triatoma is found in rocky habitats or hollow trees [19, 45]. Some species display a close relationship with one type of habitat (Rhodnius brethesi with the palm tree Leopoldina piass$a b a$, Psammolestes species with nests of Furnariidae), while others exhibit a great range of terrestrial and arboreal ecotopes (Panstrongylus megistus, $T$. dimidiata). Particularly interesting are the cases of $T$. infestans and Triatoma sordida, in which wild populations at high altitudes live in rock-piles while those in lowlands are found in hollow trees [85]. Such species provide good models for studying the pressure of habitat on morphology, genetic traits and behavior in Triatominae.

All species of Triatominae were originally sylvatic and, among them, only a small number were successful in establishing domestic colonies, thus potentially becoming involved in transmission of T. cruzi to humans. The anthropogenic environmental changes and ensuing damages to triatomine natural biotopes seem to favor the synanthropic process. However, the basic mechanisms of adaptation of these insects to artificial ecotopes remain poorly understood. We do not know if only some of the sylvatic genotypes/haplotypes may be successful in the process of adaptation. Nevertheless, the trends toward domesticity seem to be associated with behavioral plasticity, a reduction of the genetic repertoire and increasing developmental instability, making a triatomine species/population a more efficient vector as well as a more vulnerable target for control measures [17, 119].

The classification of the Triatominae based on synanthropic process is most often adopted [119]. Among the neotropical species that have proven adaptable to human dwellings are T. infestans in the Southern Cone countries (Fig. 7), R. prolixus in Colombia, Venezuela, and also in parts of Central America, and T. dimidiata, a species distributed from northern South America to Central America and Mexico. Proof of the epidemiological importance of these insects lies in the $65 \%$ reduction in the incidence of Chagas disease in Latin America that followed the elimination of synanthropic populations of these insects over large areas [119]. Long considered exclusively domestic species or species with limited wild populations, $T$. infestans and $R$. prolixus actually have a large sylvatic distribution in Bolivia and Venezuela, respectively [41, 84]. Wild T. infestans inhabits tree holes in the Chaco and can be found under large piles of rocks in the Andean valleys [25, 84]. Over its entire range, this vector colonizes rural as well as urban areas and has proven highly adaptative to human dwellings. $R$. prolixus is an arboreal species living in palm trees and can reach very high population densities in houses [105]. There is clear evidence of genome reduction in 


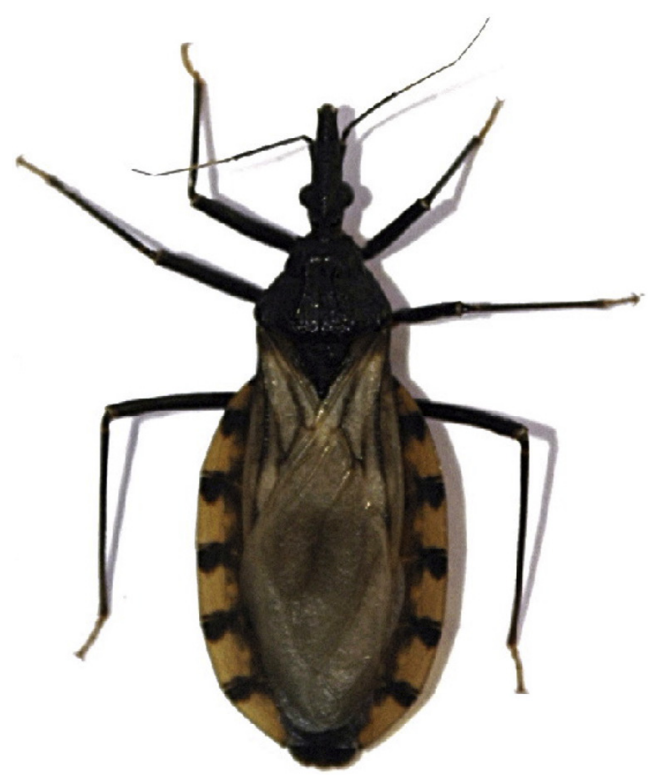

Figure 7. Sylvatic form of Triatoma infestans, the main vector of Chagas disease in the Southern Cone countries. (A color version of this figure is available at www.vetres.org.)

derived populations of $T$. infestans from the lowlands of the Southern Cone countries compared with their putative ancestral populations from the Bolivian Andes [89]. Similarly, R. prolixus in Central America has a reduced genome compared to ancestral populations in Venezuela and Colombia [35]. T. dimidiata displays a great diversity in its biology and behavior across its geographic range and has the ability to transmit $T$. cruzi to humans at a very low density [34]. Human intervention has led to the passive dispersal and subsequent colonization of new areas by synanthropic populations of these vectors $[34,35,90]$. Wild populations of these three vectors may be potential sources of reinfestation of treated areas with epidemiological consequences [34, 41, 85]. Another major obstacle to the control of these main vectors may stem from a reduction in the effectiveness of the insecticides used. For example, in $T$. infestans, high resistance to pyrethroid insecticides has been recently associated with ineffective field treatments in northern Argentina and southern Bolivia [92, 114].
Besides these primary vectors, other triatomine species are displaying synanthropic trends. Based on their geographical distribution, ability for colonizing artificial structures and vectorial capacity, they are named secondary species (Triatoma brasiliensis, T. barberi, P. megistus...) or vector candidates (T. sordida, Triatoma pseudomaculata...) [84]. The secondary species are capable of colonizing dwellings in the absence of a primary species whereas the vector candidates are poorly adapted to living in houses and instead build colonies in the peridomestic environment [32]. Traditional control approaches involving household insecticide spraying are unlikely to be effective against these vectors that keep a sylvatic habitat.

Cryptic species seem to be evenly distributed among Triatominae as they are among other major metazoan taxa [91]. Cryptospeciation was described in the genera Triatoma (T. brasiliensis, T. dimidiata, T. sordida) and Rhodnius ( $R$. robustus, $R$. ecuadoriensis) $[1,79,80,83,90]$. More surprising, some triatomine species display considerable phenotypic variability. In $T$. infestans, four morphs exhibiting obvious chromatic and morphological differences were observed [25, 48, 82]. As the different morphs occupy distinct biotopes (hollow tree, palm tree, rock) and biogeographic regions, the plasticity displayed by the wild T. infestans supports the theory suggesting the occurrence of rapid morphological divergence in response to different ecological factors [36].

\section{INTERACTIONS WITHIN THE SYSTEM}

\subsection{Interactions between $T$. cruzi and triatomine bugs, and vectorial capacity}

The localization of $T$. cruzi in the insect vector gut entails a series of morphological and physiological transformations that take place at different sites along the digestive tube of the vector (Fig. 8). Morphological changes involve passage from the unreplicative blood trypomastigote form, which is ingested with a blood meal from an infected host, through the replicative epimastigote stage, to reach the 


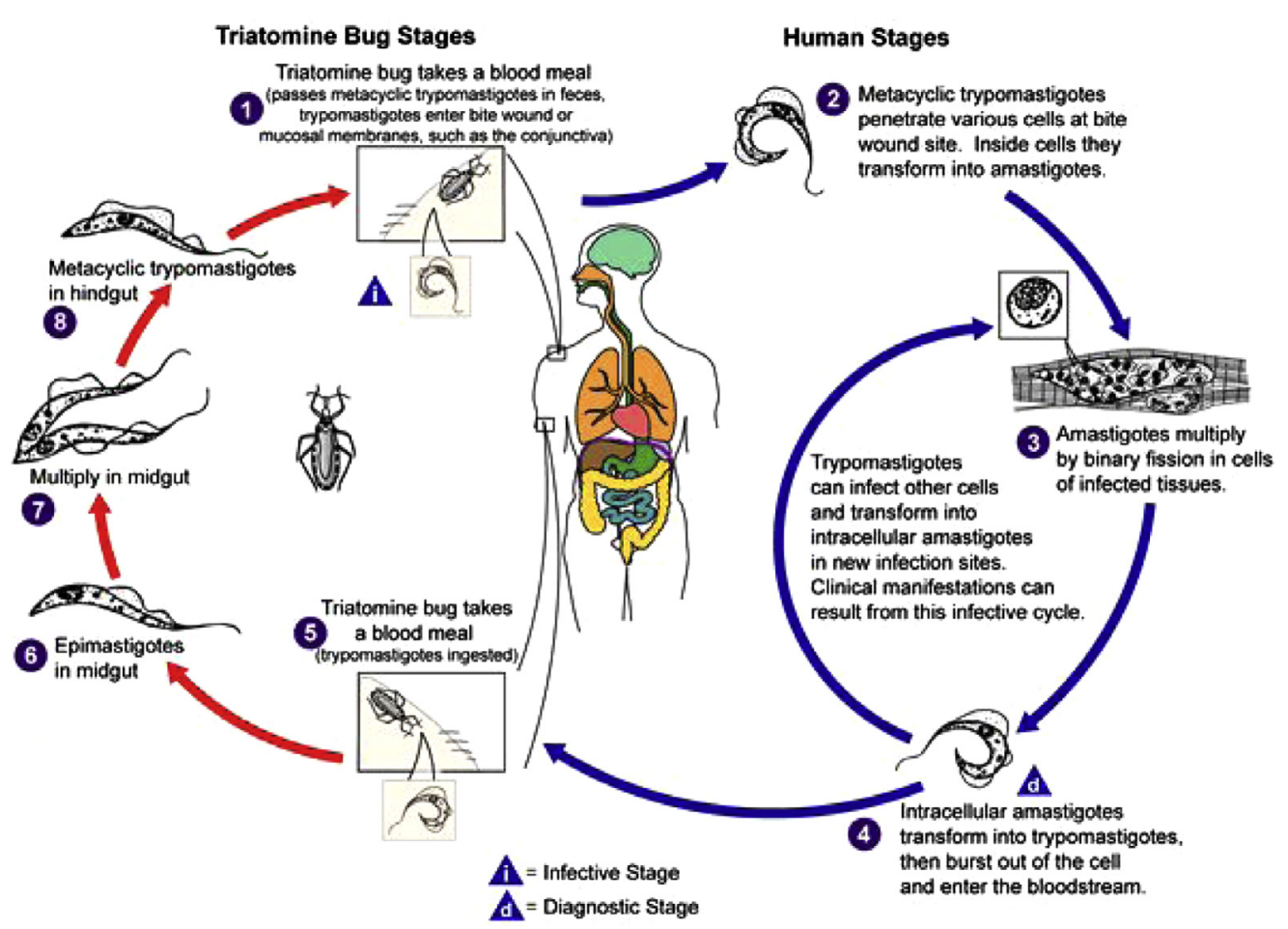

Figure 8. T. cruzi life cycle. From the DPDx Parasite Image Library of the CDC (http://www.dpd.cdc.gov/ dpdx). (A color version of this figure is available at www.vetres.org.)

infective metacyclic trypomastigote stage. The blood trypomastigote to epimastigote transformation takes place in the anterior part of the midgut, and subsequently, epimastigotes undergo binary divisions mainly in the posterior part of the midgut. Finally, epimastigotes reach the rectum and attach to the rectal cuticle, where they transform into metacyclic trypomastogotes, which will be eliminated with the insect feces and will be able to infect mammals [115]. At each one of these steps, vector-parasite interactions occur and parasites are exposed to a series of factors that will influence their viability. It has been postulated that viability of $T$. cruzi within the digestive tract of the vector, largely depends on the host nutritional state, the parasite strain, trypanolytic compounds, digestive enzymes, lectins, resident bacteria in the gut, and the endocrine system of the insect vector [44].
Two main approaches have been used to study interactions between vector and parasite in Chagas disease. The first one of these, that can be called the "molecular and biochemical approach", involves studies that deal with biochemical and molecular factors that may be involved in the mechanisms determining both the viability and the morphologicalphysiological changes that $T$. cruzi undergoes within the insect vector. The second approach, that can be called the "transmissibility approach", involves a wide range of studies that deal with the differential capacity of triatomine species to transmit $T$. cruzi.

From the "molecular and biochemical approach", it must be considered that through T. cruzi passage and multiplication within the digestive tube of the insect vector, the parasites are exposed to hostile environments, and also to 
factors that may act as signals to induce morphological and physiological changes. The mechanisms by which parasites evade potentially harmful insect factors are not well understood yet, however the widely diversified gene families that encode for surface molecules, some of which are differentially expressed in the different morphological stages of the parasite, are hypothesized to be involved [119]. Notably, some of the different insect factors to which parasites are exposed are well-described. Crop hemolytic factor, which lyses the erythrocyte membrane and releases free hemoglobin for digestion, and lectins have been suggested as possible modulators of multiplication and transformation of $T$. cruzi [44]. Differential agglutinin and lysin activities in the gut of $R$. prolixus toward different strains of $T$. cruzi have also been reported [77]. Furthermore, correlations among infectivity, differences in the surface carbohydrates of each parasite strain, and both agglutination and lytic characteristics for these strains have been observed, suggesting a strong influence of some parasite surface molecules on their infectivity to the insect vector [77]. Cysteine proteases and a cDNA encoding for a lysozyme from the gut of $T$. infestans have also been described, but their role as possible vector-parasite interaction factors has not yet been elucidated [64, 65]. Another factor that could be involved in the success of vector infection by $T$. cruzi, at least indirectly, is the presence of symbionts in the digestive tube of triatomines. It is possible that many vitamins and nutrients absent in the diet of feeding blood insects, such as triatomines, are supplied by symbionts that live in their intestines. This was demonstrated with the bacterium Rhodococcus rhodnii, which supplies nutrients to the insect $R$. prolixus [10]. The presence of symbionts could reduce the needed concentrations of components of the vector humoral immune system, such as defensin molecules, in the digestive tube of triatomines [73]. This environment of lower humoral immune components could consequently be advantageous for T. cruzi development. During development within the insect vector, T. cruzi must attach to different epithelial cell surfaces along the digestive tube. These processes of attachment involve recognition between parasite-vector cell surface molecules. Some of these molecules have been identified and found to be differentially expressed during the metacyclogenesis process wherein epimastigotes are transformed into metacyclic trypomastigotes. For example, it has been shown that the gene encoding a 7-kDa protein belonging to a chitin-binding-like protein gene family displays maximal synthesis levels in differentiating epimastigotes [27]. This and other related data suggest an elaborate molecular system involved in attachment of parasites to the rectal wall, which is thought to correlate with metacyclogenesis $[2,62]$.

Data gathered using the "transmissibility approach" suggest that there are differences in vectorial capacity among different species of triatomines, increased transmissibility when T. cruzi strains and triatomine bugs from the same region are involved, and differences in transmissibility for each parasite lineage in the same vector species (T. infestans) [16, 30, 31]. Serial xenodiagnosis performed on dogs showed that vectors from a given area are more susceptible to local strains of $T$. cruzi [31]. More recently, a higher capacity of the Chilean triatomine Mepraia spinolai to host and foster the reproduction of different $T$. cruzi lineages (T. cruzi I, IIb, IIc and IIe) was demonstrated compared to that of $T$. infestans. The $M$. spinolai used in that study was a wild vector from the same area where the $T$. cruzi isolates were obtained [16]. The data cited above suggest some degree of interaction among triatomine species and T. cruzi lineages. However, more studies are needed to elucidate whether these interactions do occur, and to understand the nature of these phenomena.

\subsection{T. cruzi transmision to animals and humans}

The classical theory regarding the natural history of Chagas disease proposes that humans were included in the $T$. cruzi transmission cycle (i) as a consequence to the acquisition of sedentary habits brought about by domestication of plants and animals or (ii) as a consequence of the colonization by triatomine vectors of human dwellings built after European colonization [100]. Either way, the new 
ecological environment favored domestication of $T$. infestans and, as a consequence, transmission of $T$. cruzi to humans. Nevertheless, recent paleoepidemiological studies reported the antiquity of human T. cruzi infections in the Andean region and more recently in Brazil, in organic remains of hunter and gatherer people $[5,69]$. Megacolon, a typical lesion of chronic Chagas disease, has been observed in Chilean and Peruvian mummies up to 9000 years old [5]. This diagnosis was confirmed by the recovery of $T$. cruzi kDNA in these mummy samples. Infection by the TCI genotype of a 7000 years old human sample was also shown, in Minas Gerais State, Brazil, where contemporary cases of Chagas disease are now predominantly TCII [69]. Hunters and gatherers were described as consumers of raw meat since remnants of raw bones and rodent fur have been detected in human coprolites [94]. Therefore, it is clear T. cruzi infection and Chagas disease preceded European colonization of the continent, and that this parasite has infected humans since their entry in the Americas. These data also suggest that the current microepidemic outbreaks of Chagas disease in the Amazon basin reflect a reemergence of this ancient epidemiological cycle in the Americas since the oral route of infection is very efficient and the acidic environment of the stomach enhances the infection competence of $T$. cruzi [122]. Among wild mammals, this route is more probable than infection through metacyclic forms voided in feces of triatomines that must pass through the dense fur of the animal. Furthermore, in the last three years, orally acquired $T$. cruzi infections attributed to the ingestion of food contamined by metacyclic forms have become more frequent and several human cases have been reported.

The study of wild and domestic mammals in human Chagas disease outbreak areas characterized by oral infection has produced distinct enzootical pictures. The first one of these is a classical picture of acquisition of Chagas disease by entrance of humans into the T. cruzi transmission cycle in the wild where patches of forest are still preserved, with all representatives of the local wild fauna infected by the parasite. Here, a panzootic scenario is observed and high parasitemia levels are detected in wild mammals of all local ecological strata. The second picture is of disease outbreaks resulting as the consequence of the reduction of mammalian fauna and the selection of new suitable reservoir hosts for T. cruzi. As a common point between the two pictures, it was observed that domestic animals were highly exposed to infection, showing that these animals should be considered as sentinels for $T$. cruzi transmission in the environment [98].

\subsection{Interaction between Triatominae and their hosts}

All members of the Triatominae subfamily are hematophagous, which is considered to be a recent characteristic in evolutionary terms. Likewise, the five nymphal instars and the adult stage are generally hematophagous. Triatomines probably evolved from predatory reduvids (catching and eating other arthropods) in response to the availability of vertebrate food source in animal refuges and nesting sites, and underwent modifications in their buccal and digestive apparatuses during this process $[21,106]$. However, primitive alimentary behavior still occurs in some triatomine species, which can feed on arthropods (Fig. 9) [78, 102]. Such a behavior seems to be more related to hemolymphagy than predation, where predigestion of tissues occurs followed by the death of the prey. A cleptohematophagous behavior (sucking blood from recently fed triatomines) could be a transitional stage between predation and hematophagy. Such observations suggest that adaptation to hematophagy is still occurring in Triatominae [20].

Triatomines belong to the group of vesselfeeding insects that use their proboscis as a needle to cannulate a host blood vessel from where they suck the blood. Obtaining a large blood meal is a time consuming and challenging task, and requires a great adaptation. Hematophagous adaptive evolution is reflected in the composition of the saliva, where various compounds are able to counteract the host hemostatic response and overcome vasoconstriction, coagulation and platelet aggregation. Antiplatelet and vasodilator activity levels are correlated 


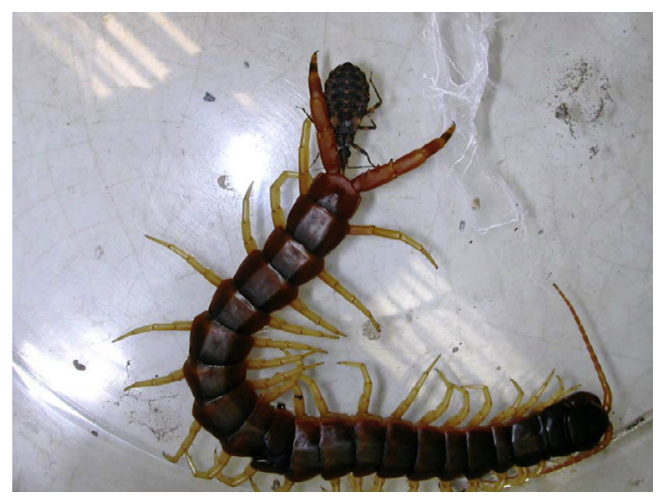

Figure 9. Triatoma brasiliensis nymphal instar feeding on the hemolymph of an immobilized scolopendra. (A color version of this figure is available at www.vetres.org.)

with blood feeding efficiencies in different triatomine species [95]. Triatomines are not that different from Reduviidae predators in habitat and forms. However, they ingest blood through a painless bite whereas the bite from Reduviidae predators tends to be very painful [106]. An action of triatomine saliva on sodium channels could be associated with loss of host sensibility at the bite site during the blood feeding process [28]. Hematophagy also requires a rapid compensation for the enormous amount of blood that triatomines ingest. The insect therefore immediately excretes great amounts of water and salts immediately to reduce its weight after a meal. Another adaptation to hematophagy is the erythrocytic rupture and hemolytic process that occurs at the beginning of digestion [21]. Sometimes, Chagas disease vectors can induce significant blood loss in their hosts in cases of massive domestic infestation [103].

A primary close association between Rhodnius species and marsupials, and between Triatoma species and rodents/edentates, was suggested in studies of the associated trypanosomes strains [45]. Similarly, it is suggested that the Panstrongylus species might be primarily associated with marsupials whereas the terrestrial species may also have been associated with edentates. Later, host transfers occurred to other sylvatic and synanthropic animals, which may or may not be considered reservoir hosts of T. cruzi. Some triatomine species are highly adapted to a single host and are able to survive only in the microhabitat occupied by this particular host. Other species are more eclectic and can adapt more easily to different hosts. Unfavorable environmental changes and the subsequent rarefaction that occurs in wild fauna may conduce triatomines to move to man-made habitats, which are highly stable and offer a variety of hiding places and an abundance of food throughout the year [119].

The identification of feeding sources is very helpful in characterizing feeding habits of triatomine populations in wild, peridomestic or domestic environments, allowing for the recognition of synanthropic animal species that may favor colonization and long-term infestation of human habitats, and assessment of the importance of contacts between humans and vectors [11]. Nevertheless, faulty sampling may bias the studies and the conclusions about the blood sources of a triatomine species often refer exclusively to domestic/peridomestic colonies, ignoring the preferences of these species in natural environments.

To avoid predatory vertebrates in the nests and burrows, Triatominae adopted cryptic behaviors and inverse activity patterns, feeding while the vertebrates are asleep. Most triatomines exhibit typically nocturnal habits in discrete temporal windows, such as responsiveness to host odors early in the night $[66,74]$. The heat radiated by warm-blooded animals appears to be the major cue used by Triatominae to locate a host. Besides the thermal cue, carbon dioxide has been shown to attract triatomine bugs similar to almost every blood-sucking arthropod [9]. Other chemical cues related to host detection have also been identified in Triatominae. Among the constituents of vertebrate odor, isobutyric acid, ammonia and aliphatic aldehydes have been shown to play an important role in host location by triatomines $[47,109]$.

\section{CONCLUSIONS}

The common pattern of $T$. cruzi vectorial transmission in humans is being supplanted 
by emerging patterns involving sylvatic triatomines that display synanthropic trends. In terms of wild animal hosts, an increase in the population of highly competent mammalian reservoirs is currently observed. In both cases, unfavorable environmental changes and the subsequent rarefaction that occurs in wild fauna diversity favor these processes. These epidemiological modifications are inducing new specific problems such as challenges in the assessment of new transmission risks, the possible emergence of an atypical physiopathology of the disease linked to infection by sylvatic parasite strains and, finally, the need for adjustments of the traditional control approaches and entomological vigilance. The currently available data show a great genetic diversity within $T$. cruzi and the existence of very divergent lineages, some of them associated with domestic cycles. Furthermore, all T. cruzi lineages and sublineages reported so far have been found in wild cycles. These cycles could act as a source of parasite for domestic transmission. In spite of the successful control of the intradomiciliary transmission of $T$. cruzi, the diversity of the infection mechanisms in addition to the numerous vector and mammalian host species makes the maintenance of sustainable surveillance activities a necessity. This will only be possible if all components of the transmission network are identified.

Acknowledgements. We thank Juan José Lauthier for the graphical design. We are grateful to Angel Marcelo Padilla and Cecilia Perez Brandán for their useful suggestions and comments.

\section{REFERENCES}

[1] Abad-Franch F., Monteiro F.A., Molecular research and the control of Chagas disease vectors, An. Acad. Bras. Cienc. (2005) 77:437-454.

[2] Andrade A.F.B., Esteves M.J.G., Angluster J., Gonzalez-Perdomo M., Goldenberg S., Changes in cell surface carbohydrates of Trypanosoma cruzi during metacyclogenesis under chemically defined conditions, J. Gen. Microbiol. (1991) 137:2845-2849.

[3] Anonymous, Recommendations from a satellite meeting, Mem. Inst. Oswaldo Cruz (1999) 94: 429-432.
[4] Ashford R.W., Leishmaniasis reservoirs and their significance in control, Clin. Dermatol. (1996) 14:523-532.

[5] Aufderheide A.C., Salo W., Madden M., Streitz J., Buikstra J., Guhl F., et al., A 9000-year record of Chagas' disease, Proc. Natl. Acad. Sci. USA (2004) 101:2034-2039.

[6] Ault S.K., Pan American Health Organization's Regional Strategic Framework for addressing neglected diseases in neglected populations in Latin America and the Caribbean, Mem. Inst. Oswaldo Cruz (2007) 102 (Suppl. I):99-107.

[7] Barnabé C., Brisse S., Tibayrenc M., Population structure and genetic typing of Trypanosoma cruzi, the agent of Chagas disease: a multilocus enzyme electrophoresis approach, Parasitology (2000) 120: 513-526.

[8] Barretto M.P., Reservoirs of Trypanosoma cruzi in the Americas, Rev. Bras. Malariol. Doenças Trop. (1964) 4:527-552.

[9] Barrozo R.B., Lazzari C.R., The response of the blood-sucking bug Triatoma infestans to carbon dioxide and other host odours, Chem. Senses (2004) 29:319-329.

[10] Beard C.B., Cordon-Rosales C., Durvasula R.V., Bacterial symbionts of the Triatominae and their potential use in control of Chagas disease transmission, Annu. Rev. Entomol. (2002) 47:123-141.

[11] Bosseno M.F., Garcia L.S., Baunaure F., Magallón-Gastélum E., Gutierrez M.S., Kasten F.L., et al., Identification in triatomine vectors of feeding sources and Trypanosoma cruzi variants by Heteroduplex Assay and a Multiplex Miniexon Polymerase Chain Reaction, Am. J. Trop. Med. Hyg. (2006) 74:303-305.

[12] Briones M.R., Souto R.P., Stolf B.S., Zingales B., The evolution of two Trypanosoma cruzi subgroups inferred from rRNA genes can be correlated with the interchange of American mammalian faunas in the Cenozoic and has implications to pathogenicity and host specificity, Mol. Biochem. Parasitol. (1999) 104:219-232.

[13] Brisse S., Barnabé C., Bañuls A.L., Sidibé I., Noël S., Tibayrenc M., A phylogenetic analysis of the Trypanosoma cruzi genome project CL Brener reference strain by multilocus enzyme electrophoresis and random amplified polymorphic DNA fingerprinting, Mol. Biochem. Parasitol. (1998) 92:253-263.

[14] Brisse S., Barnabé C., Tibayrenc M., Identification of six Trypanosoma cruzi phylogenetic lineages by random ampliyed polymorphic DNA and multilocus enzyme electrophoresis, Int. J. Parasitol. (2000) $30: 35-44$. 
[15] Brisse S., Verhoef J., Tibayrenc M., Characterisation of large and small subunit rRNA and mini-exon genes further supports the distinction of six Trypanosoma cruzi lineages, Int. J. Parasitol. (2001) 31:1218-1226.

[16] Campos R., Acuña-Retamar M., Botto-Mahan C., Ortiz S., Cattan P.E., Solari A., Susceptibility of Mepraia spinolai and Triatoma infestans to different Trypanosoma cruzi strains from naturally infected rodent hosts, Acta Trop. (2007) 104:25-29.

[17] Carbajal de la Fuente A.L., Dias-Lima A., Lopes C.M., Emperaire L., Walter A., Ferreira A., et al., Behavioral plasticity of triatominae related to habitat selection in northeast Brazil, J. Med. Entomol. (2008) 45:14-19.

[18] Carcavallo R.U., Galindez Girón I., Jurberg J., Galvão C., Lent H., Pictorial keys for tribes, genera and species for the subfamily Triatominae, in: Carcavallo R.U., Galíndez Girón I., Jurberg J., Lent H. (Eds.), Atlas of Chagas disease vectors in the Americas, Vol. I, Fiocruz, Rio de Janeiro, 1997, pp. 107-244.

[19] Carcavallo R.U., Franca Rodríguez M.E., Salvatella R., Curto de Casas S.I., Sherlock I.A., Galvão C., et al., Habitats and related fauna, in: Carcavallo R.U., Galíndez Girón I., Jurberg J., Lent H. (Eds.), Atlas of Chagas disease vectors in the Americas, Vol. II, Fiocruz, Rio de Janeiro, 1998, pp. 561-600.

[20] Carcavallo R.U., Rocha D.S., Galíndez Girón I., Sherlock I.A., Galvão C., Martínez A., et al., Feeding sources and patterns, in: Carcavallo R.U., Galíndez Girón I., Jurberg J., Lent H. (Eds.), Atlas of Chagas disease vectors in the Americas, Vol. II, Fiocruz, Rio de Janeiro, 1998, pp. 537-560.

[21] Carcavallo R.U., Jurberg J., Lent H., Phylogeny of the Triatominae, in: Carcavallo R.U., Galíndez Girón I., Jurberg J., Lent H. (Eds.), Atlas of Chagas disease vectors in the Americas, Vol. III, Fiocruz, Rio de Janeiro, 1999, pp. 925-969.

[22] Carrasco H.J., Frame I.A., Valente S.A., Miles M.A., Genetic exchange as a possible source of genomic diversity in sylvatic populations of Trypanosoma cruzi, Am. J. Trop. Med. Hyg. (1996) 54: 418-424.

[23] Carreira J.C.A., Jansen A.M., de Nazareth Meirelles M., Costa e Silva F., Lenzi H.L., Trypanosoma cruzi in the scent glands of Didelphis marsupialis: the kinetics of colonization, Exp. Parasitol. (2001) 97:129-140.

[24] Chagas C., Nova tripanosomiase humana. Estudos sobre a morfología e o ciclo evolutivo do Schizotrypanum cruzi, n. gen., n. sp., agente etiológico de nova entidade mórbida do homem, Mem. Inst. Oswaldo Cruz (1909) 1:159-218.
[25] Cortez M.R., Emperaire L., Piccinali R.V., Gürtler R.E., Torrico F., Jansen A.M., Noireau F., Sylvatic Triatoma infestans (Reduviidae, Triatominae) in the Andean valleys of Bolivia, Acta Trop. (2007) 102:47-54

[26] Crisante G., Rojas A., Teixeira M.M., Añez N., Infected $\operatorname{dogs}$ as a risk factor in the transmission of human Trypanosoma cruzi infection in western Venezuela, Acta Trop. (2006) 98:247-254.

[27] Dallagiovanna B., Plazanet-Menut C., Ogatta S.F.Y., Trypanosoma cruzi: a gene family encoding chitin-binding-like proteins is posttranscriptionally regulated during metacyclogenesis, Exp. Parasitol. (2001) 99:7-16.

[28] Dan A., Pereira M.H., Pesquero J.L., Diotaiuti L., Lacerda B., Paulo S., Action of the saliva of Triatoma infestans (Heteroptera: Reduviidae) on sodium channels, J. Med. Entomol. (1999) 36:875-879.

[29] Deane M.P., Lenzi H.L., Jansen A.M., Trypanosoma cruzi: vertebrate and invertebrate cycles in the same mammal host, the opossum Didelphis marsupialis, Mem. Inst. Oswaldo Cruz (1984) 79:513-515.

[30] De Lana M., Silveira Pinto A., Barnabé C., Quesney V., Noël S., Tibayrenc M., Trypanosoma cruzi: compared vectorial transmissibility of three major clonal genotypes by Triatoma infestans, Exp. Parasitol. (1998) 90:20-25.

[31] Dias E., Técnica do xenodiagnóstico na moléstia de Chagas, Mem. Inst. Oswaldo Cruz (1940) 35: 335-342.

[32] Dias J.C.P., Diotaiuti L., Vectores secundarios de la enfermedad de Chagas en el Brasil y perspectivas para su control, in: Guhl F., Jaramillo C.A. (Eds.), Curso taller control de tripanosomiasis americana y leishmaniosis: aspectos biológicos, genéticos y moleculares, Corcas editores Ltda, Santafé de Bogotá, D.C., Colombia, 1998, pp. 154-159.

[33] Diosque P., Barnabé C., Padilla A.M., Marco J.D., Cardozo R.M., Cimino R.O., et al., Multilocus enzyme electrophoresis analysis of Trypanosoma cruzi isolates from a geographically restricted endemic area for Chagas disease in Argentina, Int. J. Parasitol. (2003) 33:997-1003.

[34] Dorn P.L., Monroy C., Curtis A., Triatoma dimidiata (Latreille, 1811): a review of its diversity across its geographic range and the relationship among populations, Infect. Genet. Evol. (2007) 7:343-352.

[35] Dujardin J.P., Muñoz M., Chavez T., Ponce C., Moreno J., Schofield C.J., The origin of Rhodnius prolixus in Central America, Med. Vet. Entomol. (1998) 12:113-115. 
[36] Dujardin J.P., Panzera P., Schofield C.J., Triatominae as a model of morphological plasticity under ecological pressure, Mem. Inst. Oswaldo Cruz (1999) 94:223-228.

[37] Estrada-Franco J.G., Bhatia V., Diaz-Albiter H., Ochoa-Garcia L., Barbabosa A., Vazquez-Chagoyan J.C., et al., Human Trypanosoma cruzi infection and seropositivity in dogs, Mexico, Emerg. Infect. Dis. (2006) 12:624-630.

[38] Fernandes O., Sturm N.R., Derre R., Campbell D.A., The miniexon gene: a genetic marker for zymodeme III of Trypanosoma cruzi, Mol. Biochem. Parasitol. (1998) 95:129-133.

[39] Fernandes O., Souto R.P., Castro J.A., Pereira J.B., Fernandes N.C., Junqueira A.C., et al., Brazilian isolates of Trypanosoma cruzi from humans and triatomines classified into two lineages using miniexon and ribosomal RNA sequences, Am. J. Trop. Med. Hyg. (1998) 58:807-811.

[40] Fernandes O., Mangia R.H., Lisboa C.V., Pinho A.P., Morel C.M., Zingales B., et al., The complexity of the sylvatic cycle of Trypanosoma cruzi in Rio de Janeiro state (Brazil) revealed by the non-transcribed spacer of the mini-exon gene, Parasitology (1999) 118:161-166.

[41] Fitzpatrick S., Feliciangeli M.D., SanchezMartin M.J., Monteiro F.A., Miles M.A., Molecular genetics reveal that silvatic Rhodnius prolixus do colonise rural houses, PLoS Negl. Trop. Dis. (2008) $2: \mathrm{e} 210$.

[42] Flynn J.J., Wyss A.R., Recent advances in South American mammalian paleontology, Tree (1998) 13:449-454.

[43] Galvão C., Carcavallo R., Rocha D.S., Jurberg J., A checklist of the current valid species of the subfamily Triatominae Jeannel, 1919 (Hemiptera, Reduviidae) and their geographical distribution, with nomenclature and taxonomic notes, Zootaxa (2003) 202:1-36.

[44] Garcia E.S., Ratcliffe N.A., Whitten M.M., Gonzalez M.S., Azambuja P., Exploring the role of insect host factors in the dynamics of Trypanosoma cruzi-Rhodnius prolixus interactions, J. Insect Physiol. (2007) 53:11-21.

[45] Gaunt M., Miles M., The ecotopes and evolution of triatomine bugs (Triatominae) and their associated trypanosomes, Mem. Inst. Oswaldo Cruz (2000) 95:557-565.

[46] Gaunt M.W., Yeo M., Frame I.A., Stothard J.R., Carrasco H.J., Taylor M.C., et al., Mechanism of genetic exchange in American trypanosomes, Nature (2003) 421:936-939.
[47] Guerenstein P.G., Guerin P.M., Olfactory and behavioural responses of the blood-sucking bug Triatoma infestans to odours of vertebrate hosts, J. Exp. Biol. (2001) 204:585-597.

[48] Gumiel M., Catalá S., Noireau F., Rojas De Arias A., García A., Dujardin J.P., Wing geometry in Triatoma infestans (Klug) and T. melanosoma Martinez, Olmedo \& Carcavallo (Hemiptera: Reduviidae), Syst. Entomol. (2003) 28:173-180.

[49] Gürtler R.E., Cecere M.C., Lauricella M.A., Cardinal M.V., Kitron U., Cohen J.E., Domestic dogs and cats as sources of Trypanosoma cruzi infection in rural northwestern Argentina, Parasitology (2007) 134:69-82.

[50] Hamilton P.B., Gibson W.C., Stevens J.R., Patterns of co-evolution between trypanosomes and their hosts deduced from ribosomal RNA and proteincoding gene phylogenies, Mol. Phylogenet. Evol. (2007) 44:15-25.

[51] Hancock K., Zajac A.M., Pung O.J., Elvinger F., Rosypal A.C., Lindsay D.S., Prevalence of antibodies to Trypanosoma cruzi in raccoons (Procyon lotor) from an urban area of northern Virginia, J. Parasitol. (2005) 91:470-472.

[52] Herrera H.M., Abreu U.G., Keuroghlian A., Freitas T.P., Jansen A.M., The role played by sympatric collared peccary (Tayassu tajacu), white-lipped peccary (Tayassu peccary) and feral pig (Sus scrofa) as maintenance hosts for Trypanosoma evansi and Trypanosoma cruzi in a sylvatic area of Brazil, Parasitol. Res. (2008) 103:619-624.

[53] Herrera H.M., Rademaker V., Abreu U.G., D'Andrea P.S., Jansen A.M., Variables that modulate the spatial distribution of Trypanosoma cruzi and Trypanosoma evansi in the Brazilian Pantanal, Acta Trop. (2007) 102:55-62.

[54] Herrera H.M., Lisboa C.V., Pinho A.P., Olifiers N., Bianchi R.C., Rocha F.L., et al., The coati (Nasua nasua, Carnivora, Procyonidae) as a reservoir host for the main lineages of Trypanosoma cruzi in the Pantanal region, Brazil, Trans. R. Soc. Trop. Med. Hyg. (2008) 102:1133-1139.

[55] Herrera L., D’Andrea P.S., Xavier S.C.C., Mangia R.H., Fernandes O., Jansen A.M., Trypanosoma cruzi infection in wild mammals of the National Park "Serra da Capivara", and its surroundings (Piauí, Brazil), endemic for Chagas disease, Trans. R. Soc. Trop. Med. Hyg. (2005) 99:379-388.

[56] Hypsa V., Tietz D.F., Zrzavy J., Rego R.O.M., Galvão C., Jurberg J., Phylogeny and biogeography of Triatominae (Hemiptera: Reduviidae): molecular evidence of a New World origin of the Asiatic clade, Mol. Phylogenet. Evol. (2002) 23:447-457. 
[57] Jansen A.M., Carreira J.C., Deane M.P., Infection of a mammal by monogenetic insect trypanosomatids (Kinetoplastida, Trypanosomatidae), Mem. Inst. Oswaldo Cruz (1988) 83:271-272.

[58] Janzen D.H., When is it coevolution? Evolution (1980) 34:611-612.

[59] Kawashita S.Y., Sanson G.F., Fernandes O., Zingales B., Briones M.R., Maximum-likelihood divergence date estimates based on rRNA gene sequences suggest two scenarios of Trypanosoma cruzi intraspecific evolution, Mol. Biol. Evol. (2001) 18:2250-2259.

[60] Kierszenbaum F., Gottlieb C.A., Budzko D.B., Antibody-independent, natural resistance of birds to Trypanosoma cruzi infection, J. Parasitol. (1981) 67:656-660.

[61] Kjos S.A., Snowden K.F., Craig T.M., Lewis B., Ronald N., Olson J.K., Distribution and characterization of canine Chagas disease in Texas, Vet. Parasitol. (2008) 15:249-256.

[62] Kollien A.H., Schmidt J., Schaub G.A., Modes of association of Trypanosoma cruzi with the intestinal tract of the vector Triatoma infestans, Acta Trop. (1998) 30:127-141.

[63] Kollien A.H., Schaub G.A., The development of Trypanosoma cruzi in Triatominae, Parasitol. Today (2000) 16:381-387.

[64] Kollien A.H., Fechner S., Waniek P.J., Schaub G.A., Isolation and characterization of a cDNA encoding for a lysozyme from the gut of the reduviid bug Triatoma infestans, Arch. Insect Biochem. Physiol. (2003) 53:134-145.

[65] Kollien A.H., Waniek P.J., Nisbet A.J., Billingsley P.F., Schaub G.A., Activity and sequence characterization of two cysteine proteases in the digestive tract of the reduviid bug Triatoma infestans, Insect Mol. Biol. (2004) 13:569-579.

[66] Lazzari C.R., Circadian organization of locomotion activity in the haematophagous bug Triatoma infestans, J. Insect Physiol. (1992) 38:895-903.

[67] Legey A.P., Pinho A.P., Xavier S.C., Marchevski R., Carreira J.C., Leon L.L., Jansen A.M., Trypanosoma cruzi in marsupial didelphids (Philander frenata and Didelphis marsupialis): differences in the humoral immune response in natural and experimental infections, Rev. Soc. Bras. Med. Trop. (2003) 36:241-248.

[68] Lent H., Wygodzinsky P., Revision of the Triatominae (Hemiptera, Reduviidae), and their significance as vectors of Chagas disease, Bull. Am. Mus. Nat. Hist. (1979) 163:127-520.
[69] Lima V.S., Iniguez A.M., Otsuki K., Ferreira L.F., Araújo A., Vicente A.C.P., Jansen A.M., Chagas disease by Trypanosoma cruzi lineage I in huntergatherer ancient population in Brazil, Emerg. Infect. Dis. (2008) 14:1001-1002.

[70] Lisboa C.V., Dietz J., Baker A.J., Russel N.N., Jansen A.M., Trypanosoma cruzi infection in Leontopithecus rosalia at the Reserva Biológica de Poco das Antas, Rio de Janeiro, Brazil, Mem. Inst. Oswaldo Cruz. (2000) 95:445-452.

[71] Lisboa C.V., Mangia R.H., Luz S.L., Kluczkovski A. Jr., Ferreira L.F., Ribeiro C.T., et al., Stable infection of primates with Trypanosoma cruzi I and II, Parasitology (2006) 133:603-611.

[72] Lisboa C.V., Pinho A.P., Herrera H.M., Gerhardt M., Cupolillo E., Jansen A.M., Trypanosoma cruzi (Kinetoplastida, Trypanosomatidae) genotypes in neotropical bats in Brazil, Vet. Parasitol. (2008) 156:314-318.

[73] Lopez L., Morales G., Ursic R., Wolff M., Lowenberger C., Isolation and characterization of a novel insect defensin from Rhodnius prolixus, a vector of Chagas disease, Insect Biochem. Mol. Biol. (2003) $33: 439-47$

[74] Lorenzo M.G., Lazzari C.R., Activity pattern in relation to refuge exploitation and feeding in Triatoma infestans (Hemiptera: Reduviidae), Acta Trop. (1998) $70: 163-170$

[75] Machado C.A., Ayala F.J., Nucleotide sequences provide evidence of genetic exchange among distantly related lineages of Trypanosoma cruzi, Proc. Natl. Acad. Sci. USA (2001) 98:7396-7401.

[76] Maguire J.H., Chagas' disease: can we stop the deaths? N. Engl. J. Med. (2006) 355:760-761.

[77] Mello C.B., Azambuja P., García E.S., Ratvliffe N.A., Differential in vitro and in vivo behavior of three strains of Trypanosoma cruzi in the gut and hemolymph of Rhodnius prolixus, Exp. Parasitol. (1996) $82: 112-121$.

[78] Miles M.A., de Souza A.A., Póvoa M., Chagas disease in the Amazon Basin. III. Ecotopes of ten triatomine bug species (Hemiptera, Reduviidae) from the vicinity of Belém, Pará state, Brazil, J. Med. Entomol. (1981) 18:266-278.

[79] Monteiro F.A., Barrett T.V., Fitzpatrick F., Cordon-Rosales C., Feliciangeli D., Beard C.B., Molecular phylogeography of the Amazonian Chagas disease vectors Rhodnius prolixus and $R$. robustus, Mol. Ecol. (2003) 12:997-1006.

[80] Monteiro F.A., Donnelly M.J., Beard C.B., Costa C., Nested clade and phylogeographic analyses of the 
Chagas disease vector Triatoma brasiliensis in Northeast Brazil, Mol. Phylogenet. Evol. (2004) 32:46-56.

[81] Monteiro R.V., Dietz J.M., Raboy B., Beck B., De Vleeschouwer K., Baker A., et al., Parasite community interactions: Trypanosoma cruzi and intestinal helminths infecting wild golden lion tamarins Leontopithecus rosalia and golden-headed lion tamarins L. chrysomelas (Callitrichidae, L., 1766), Parasitol. Res. (2007) 101:1689-1698.

[82] Noireau F., Flores R., Guttierez T., Dujardin J.P., Detection of sylvatic dark morphs of Triatoma infestans in the Bolivian Chaco, Mem. Inst. Oswaldo Cruz (1997) 92:583-584.

[83] Noireau F., Gutierrez T., Zegarra M., Flores R., Brenière F., Cardozo L., Dujardin J.P., Cryptic speciation in Triatoma sordida (Hemiptera: Reduviidae) from the Bolivian Chaco, Trop. Med. Int. Health (1998) 3:364-372.

[84] Noireau F., Carbajal de la Fuente A.L., Lopes C.M., Diotaiuti L., Some considerations about the ecology of Triatominae, An. Acad. Bras. Cienc. (2005) 77:431-436.

[85] Noireau F., Cortez M.R., Monteiro F.A., Jansen A.M., Torrico F., Can wild Triatoma infestans foci in Bolivia jeopardize Chagas disease control efforts? Trends Parasitol. (2005) 21:7-10.

[86] Olifiers N., Gentile R., Fiszon J.T., Relation between small-mammal species composition and anthropic variables in the Brazilian Atlantic Forest, Braz. J. Biol. (2005) 65:495-501.

[87] Oliveira R.P., Melo A.I., Macedo A.M., Chiari E., Pena S.D., The population structure of Trypanosoma cruzi: expanded analysis of 54 strains using eight polymorphic CA-repeat microsatellites, Mem. Inst. Oswaldo Cruz (1999) 94:65-70.

[88] Paige C.F., Scholl D.T., Truman R.W., Prevalence and incidence density of Mycobacterium leprae and Trypanosoma cruzi infections within a population of wild nine-banded armadillos, Am. J. Trop. Med. Hyg. (2002) 67:528-532.

[89] Panzera F., Dujardin J.P., Nicolini P., Caraccio M.N., Rose V., Tellez T., et al., Genomic changes of Chagas disease vector, South America, Emerg. Infect. Dis. (2004) 10:438-446.

[90] Panzera P., Ferrandis I., Ramsey J., Ordoñez R., Salazar-Schettino P.M., Cabrera M., et al., Chromosomal variation and genome size support existence of cryptic species of Triatoma dimidiata with different epidemiological importance as Chagas disease vectors, Trop. Med. Int. Health (2006) 11:1092-1103.

[91] Pfenninger M., Schwenk K., Cryptic animal species are homogeneously distributed among taxa and biogeographical regions, BMC Evol. Biol. (2007) 7:121-126.

[92] Picollo M.I., Vassena C., Orihuela P.S., Barrios S., Zaidemberg M., Zerba E., High resistance to pyrethroid insecticides associated with ineffective field treatments in Triatoma infestans (Hemiptera: Reduviidae) from northern Argentina, J. Med. Entomol. (2005) 42:637-642.

[93] Raccurt C.P., Trypanosoma cruzi in French Guiana: review of accumulated data since 1940, Méd. Trop. (1996) 56:79-87.

[94] Reinhard K.J., Ambler J.R., Szuter C.R., Huntergatherer use of small animal food resources: coprolite evidence, Int. J. Osteoarchaeol. (2007) 17:416-428.

[95] Ribeiro J.M., Schneider M., Isaias T., Jurberg J., Galvao C., Guimaraes J.A., Role of salivary antihemostatic components in blood feeding by triatomine bugs (Heteroptera), J. Med. Entomol. (1998) 35: 599-610.

[96] Robello C., Gamarro F., Castanys S., AlvarezValin F., Evolutionary relationships in Trypanosoma cruzi: molecular phylogenetics supports the existence of a new major lineage of strains, Gene (2000) 246:331-338.

[97] Rodriguero M.S., Gorla D., Latitudinal gradient in species richness of the New World Triatominae (Reduviidae), Global Ecol. Biogeogr. (2004) 13: 75-84.

[98] Roque A.L.R., Xavier S.C.C., Rocha M.R., Duarte A.C.M., D’Andrea P.S., Jansen A.M., Trypanosoma cruzi transmission cycle among wild and domestic mammals in three areas of orally transmitted Chagas disease outbreaks, Am. J. Trop. Med. Hyg. (2008) 79:742-749.

[99] Rosypal A.C., Cortés-Vecino J.A., Gennari S.M., Dubey J.P., Tidwell R.R., Lindsay D.S., Serological survey of Leishmania infantum and Trypanosoma cruzi in dogs from urban areas of Brazil and Colombia, Vet. Parasitol. (2007) 149:172-177.

[100] Rothhammer F., Allison M.J., Núñez L., Standen V., Arriaza B., Chagas' disease in preColumbian South America, Am. J. Phys. Anthropol. (1985) 68:495-498.

[101] Rozas M., Botto-Mahan C., Coronado X., Ortiz S., Cattan P.E., Solari A., Coexistence of Trypanosoma cruzi genotypes in wild and periodomestic mammals in Chile, Am. J. Trop. Med. Hyg. (2007) 77:647-653.

[102] Salvatella R., Calegari L., Puime A., Basmadjian Y., Rosa R., Guerrero J., et al., Perfil alimentario de Triatoma rubrovaria (Blanchard, 1843) (Hemiptera, Triatominae) en ambitos peridomiciliares de una 
localidade rural de Uruguay, Rev. Inst. Med. Trop. São Paulo (1994) 36:311-320.

[103] Schofield C.J., Chagas disease, triatomine bugs, and blood-loss, Lancet (1981) 1:1316.

[104] Schofield C.J., Biosystematics of the Triatominae. in: Service M.W. (Ed.), Biosystematics of Haematophagous Insects, Systematics Association, Special Vol. 37, Clarendon Press, Oxford, 1988, pp. 284-312.

[105] Schofield C.J., Triatominae: biology and control, Eurocommunica Publications Ed., West Sussex, UK, 1994.

[106] Schofield C.J., Trypanosoma cruzi - the vectorparasite paradox, Mem. Inst. Oswaldo Cruz (2000) 95:535-544.

[107] Schofield C.J., Jannin J., Salvatella R., The future of Chagas disease control, Trends Parasitol. (2006) 22:583-588.

[108] Souto R.P., Fernandes O., Macedo A.M., Campbell D.A., Zingales B., DNA markers define two major phylogenetic lineages of Trypanosoma cruzi, Mol. Biochem. Parasitol. (1996) 83:141-152.

[109] Taneja J., Guerin P.M., Oriented responses of triatomines bugs Rhodnius prolixus and Triatoma infestans to vertebrate odours on a servosphere, J. Comp. Physiol. A (1995) 176:455-464.

[110] Tibayrenc M., Ward P., Moya A., Ayala F.J., Natural populations of Trypanosoma cruzi, the agent of Chagas disease, have a complex multiclonal structure, Proc. Natl. Acad. Sci. USA (1986) 83:115-119.

[111] Tibayrenc M., Ayala F.J., Isozyme variability in Trypanosoma cruzi, the agent of Chagas' disease: genetical, taxonomical, and epidemiological significance, Evolution (1988) 42:277-292.

[112] Tibayrenc M., Population genetics of parasitic protozoa and other microorganisms, Adv. Parasitol. (1995) 36:47-115.

[113] Tibayrenc M., Genetic epidemiology of parasitic protozoa and other infectious agents: the need for an integrated approach, Int. J. Parasitol. (1998) 28: 85-104.
[114] Toloza A.C., Germano M., Cueto G.M., Vassena C., Zerba E., Picollo M.I., Differential patterns of insecticide resistance in eggs and first instars of Triatoma infestans (Hemiptera: Reduviidae) from Argentina and Bolivia, J. Med. Entomol. (2008) 45:421-426.

[115] Tyler K.M., Engman D.M., The life cycle of Trypanosoma cruzi revisited, Int. J. Parasitol. (2001) 31:472-481.

[116] Valente V.C., Valente S.A., Noireau F., Carrasco H.J., Miles M.A., Chagas disease in the Amazon Basin: association of Panstrongylus geniculatus (Hemiptera: Reduviidae) with domestic pigs, J. Med. Entomol. (1998) 35:99-103.

[117] Westenberger S.J., Barnabé C., Campbell D.A., Sturm N.R., Two hybridization events define the population structure of Trypanosoma cruzi, Genetics (2005) 171:527-543.

[118] Wolfe N.D., Dunavan C.P., Diamond J., Origins of major human infectious diseases, Nature (2007) 447:279-283.

[119] World Health Organization, Control of Chagas disease, Techn. Rep. Ser. No. 905, Geneva, 2002.

[120] Yaeger R.G., The prevalence of Trypanosoma cruzi infection in armadillos collected at a site near New Orleans, Louisiana, Am. J. Trop. Med. Hyg. (1988) 38:323-326.

[121] Yeo M., Acosta N., Llewellyn M., Sanchez H., Adamson S., Miles G.A., et al., Origins of Chagas disease: Didelphis species are natural hosts of Trypanosoma cruzi I and armadillos hosts of Trypanosoma cruzi II, including hybrids, Int. J. Parasitol. (2005) 35:225-233.

[122] Yoshida N., Trypanosoma cruzi infection by oral route: how the interplay between parasite and host components modulates infectivity, Parasitol. Int. (2008) 57:105-109.

[123] Zafra G., Mantilla J.C., Valadares H.M., Macedo A.M., Gonzalez C.I., Evidence of Trypanosoma cruzi II infection in Colombian chagasic patients, Parasitol. Res. (2008) 103:731-734. 